\title{
TRANSFORMING CORPORATIONS INTO CO-OPERATIONS
}

(The Humanistic Meaning of Creative Management for the World Eco-nomy)

Stephen I. Ternyik

Techno-Logos, Inc.

StephenJehucal@web.de

Social science researcher \& entrepreneur (-1985).

Knowledge is not enough, you have to apply it;

willing is not enough, you have to realize.

(J.W. Goethe)

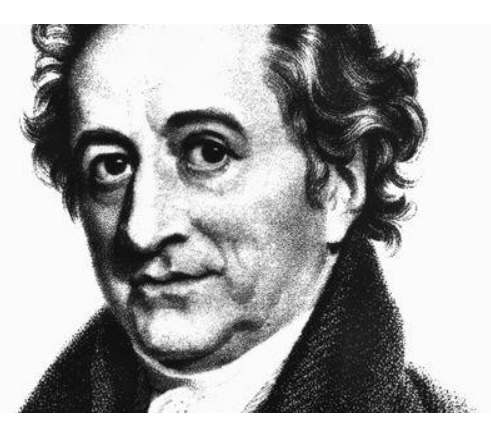

The ongoing fundamental transformation of the economy, society and the environment cannot be understood and solved with the cognitive categories of industrial thinking from the last 100 years; the true nature of this rapid change, the driving causal factors and related effects are very badly interpreted by the political and economic leadership. It is therefore extremely important to understand the original role of management for converting knowledge into value and its future potential as universal social activity, including the entrepreneurial spirit to realize 'human dreams', i.e. to realize new ideas that will work to meet pressing unmet needs. This great innovation gap ranges from the cure of human diseases over the creation of more meaningful and healthy workplaces to the mastering of coming ecological challenges; much more investment and attention need to be directed towards innovations that address these compelling human problems: the dynamic complexity of these management problems is being propelled by demographic, tech-know-logical, monetary and environmental dependencies. Furthermore, there does not exist any natural law that all human needs can 
and should be satisfied; on the contrary, every human economy can 'only' try to cover demands via purchasing power. Unfortunately, the neo-classical economics of debt or fiat credit money of the last 30 years exhausted even the purchasing power of the richest nations and will subsequently mark the end of the welfare state, but the old problems of human welfare and well-being remain the same and new ones are arising.

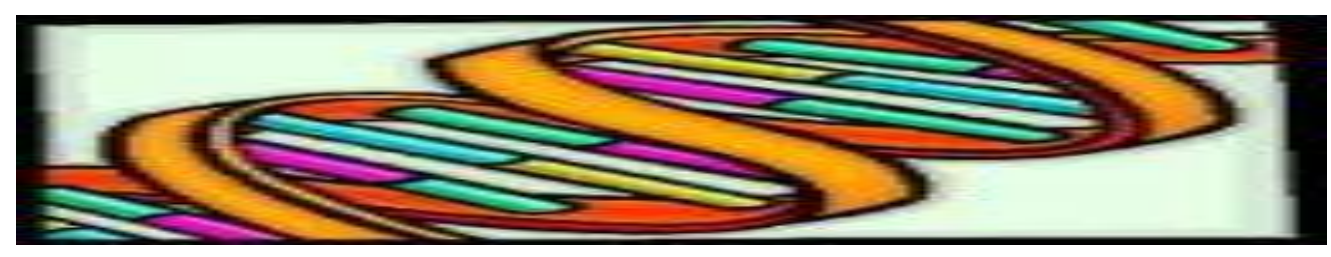

As it is impossible to translate a work from W. Shakespeare with a word pool of 2000 words from English into Latin, it is also impossible to solve the future problems of human management with the industrial knowledge of the past. The economic corporations of the human future will be transformed into eco-logical co-operations where social self-organization, self-emergence and self-regulation will play the leading role; these managerial innovations will take place via a methodical application of $4^{\text {th }}$ order cybernetics. Communicating with advanced systms variety will be the core competency of the knowledge management worker who will learn to cope with growing complexity by deducing variety into simple working formulae, logically and creatively. The basic intuition of this new selection procedure is the cybernetic discovery that all organizational systems operate and function via natural laws. As a result, the classical ways of production, distribution and consumption will change or modernize radically and this pertains to the information-processing levels of human emotion, cognition and decisionmaking likewise. This historical bifurcation or evolutionary leap implies high existential (out of control) risks and firms, households as social institutions are in need of very advanced managerial knowledge to cope with the speed and depth of this basic transformation in the value creating processes/systems of the social economy. It is empirically well known that such rapid periods of life/work style alterations do effect the deep emotion of mass psychology and that the individual liberty in free societies is factually endangered because of growing existential mass fears about economic survival; many times, a 'nuclear fusion' of the great leviathan and big business took place that led to 'central collective solutions of planning', resulting ultimately in total destruction, death and collapse. The underlying psychological cause of these material effects is that the formal systems of abstract reasoning and moral sytems of ethical behavior need to be further elaborated 'to fit' the new 
emerging situation; however, precisely these two superior human qualities are badly valued in consumer or affluent societies as main identities and principles are 'constructive' acts of purchasing 'some-thing' (you are what you are buying and possessing, some-body is traded for some-thing, to put it simply). Unfortunately, in our techno-economic stage, this expanding demand for goods is not equal to the demand for labor. From this diagnostic view follows the prognostic conclusion that an organizational evolution from corporations to co-operations is manadatory for human survival in the development of the future economy; in any case, we are in need to learn more about the selection pressure (complexity) and the selection process (strategy).
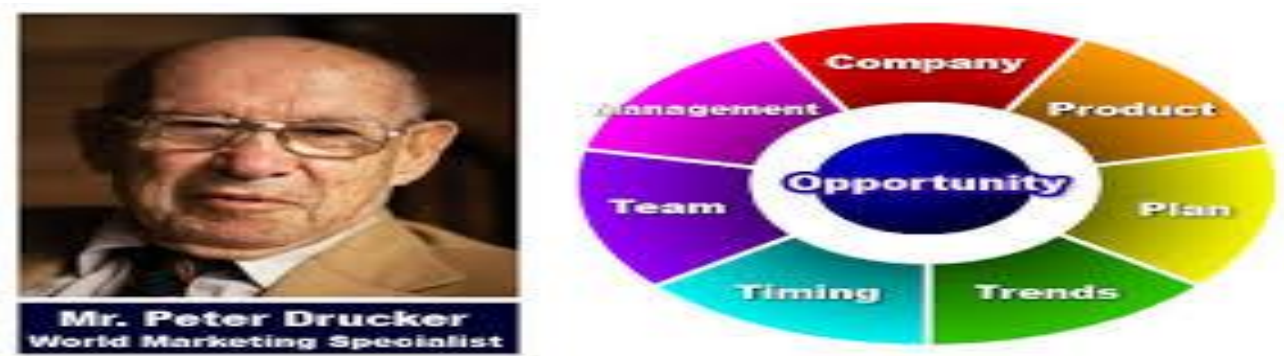

There are three overlapping fields of managerial study and activity that are calling for our full methodical attention:
A: managerial ethics;
B: managerial cybernetics;
C: managerial ecology.

Before we can elaborate on the scientific complexity and strategy of these managerial professional arts, we have to think about the dominant wealth creation theories/ideologies of the last three decades. Wealth and welfare do not result from permanently rising prices of shares and real estate; wealth and welfare do result from the development of physically productive capital like factories, machines, infrastructures, technology and knowledge. Starting from the professional viewpoint of wealth management, rising prices are always perceived, observed and measured as a warning signal and every private banking manager (and not only in $\mathrm{CH}$ or FL) knows very well to read and analyze these monetary signals that turn into economic symptoms, which in their latest stage localize as greater ill-nesses/dis-eases of the social fabric. 
The only road to wealth and welfare is the economic tool of investment; wealth and welfare creation via investments leads to more working-places, more employment and real demand. These expenditures for physical investments are leading to those incomes that do provide the purchasing power for those goods (and services), which have been produced by these physical investments. This implies economically that physical investments are covered financially by savings; therefore, in a healthy economy, the excessive expansion of bank credit money is limited by the braking system of the savings rate or proportional saving of money. The dominant orthodox wealth creation theories/ideologies of the last three decades, on the contrary, were led by the canonical monetary dogma that an economic gain in wealth can be realized by rising (manipulating) market values and valuation; practically, such a financial manipulation can only be done exponentially by higher credit risk and the continuous selling/buying of assets. However, there must be 'found some-body' who can really pay the price and who really pays; consequently, such an economic model of thought results in huge artificial transfers and concentration of wealth as a virtual number game, but it does not result in a macro-economic effect of more income for more people. On the contrary, it is managerial mischief, concerning all ethical, economic and ecological criteria involved. Furthermore, the empirical ratio of data in market economies show that medium-sized enterprises do create about $2 / 3$ of productive value and do employ the equal portion of workforce. The above mentioned wealth creation alchemy is, ultimately, the root cause of the societal polarization in national economies and the global polity, leading to unbearable mass tension in all layers of the affected populations.

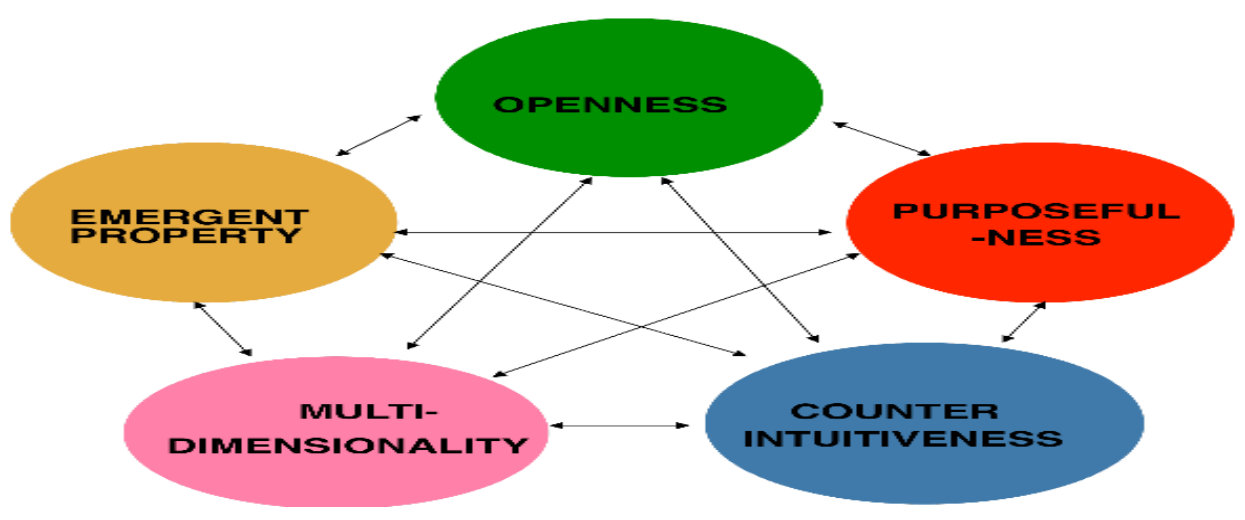

All human organizations need management, but not all of them have to focus on micro-economics, business administration and accounting. Management 
cannot be limited down to applied economics and it did also not evolve in this economic field of human activity, i.e. it is first and foremost the most important social function in human organizations, empirically and historically. Management is also not reducable to human leadership or to making a good deal in business; entrepreneurship can also not be equated with management, it is only needed when the entrepreneur wants the enterprise to grow further independently of his/her person. Many practical cultures of management do exist, but they are not identical with educational programs of certain business schools. In addition, management by objectives makes sense; but the most important objective of managerial study and activity is to convert/tranform knowledge $\&$ resources into value. In a market economy, the customer (client) is exactly willing to pay for the value of a certain product (service) and this is done by economic choices; financial gain via satisfied customers is evidently something different than profit manipulation of assets and balance sheets. The customer does not pay for the valuation of a corporation, but for the value of the product and this is the essential feedback for entrepreneurial competitiveness. Long-term cash flow and purpose of any human organization is optimally assured by creating value from knowledge \& resources. According to the mathematics and statistics of earnings after everything, financial gain does not exist in the real economy, it is only a monetary tool of management and entrepreneurial direction; actually, there are only two categories of costs: firstly, the costs of running the business organization in the present time and secondly, the costs of running the business organization in the future. The market itself is a relatively slow retro-prospective aposteriori-mechanism that can only punish for the economic lessons not learnt; no market nowhere can foretell you where to allocate your economic resources and what body of knowledge you should apply; these weaknesses of the market system can only be communicated by co-operative governance and macro-prudential tools like an institutional or organizational mission of values, identities and principles. Consequently, entrepreneurial organizations do not make money, but they do make products (services); also the printing press does not make money, it makes means of payment. Finally, the entrepreneurial organization in a market economy is based on liquidity and our current banking system, being mentally guided by the above mentioned economic errors, does not circulate this needed type of liquidity, because it mal-functions as an absorption and redistribution machine of self-manipulated profit bubbles (bubble economics). 
Every ethical system of human morality has to resolve the behavioral conflict of the 'relativity of physicalities of this world' versus the 'absoluteness of ethical standards', i.e. managerial ethics cannot be performed in an economic vacuum, but has direct physical and moral effects on all living beings (plants, animals, humans). Managerial cybernetics of $4^{\text {th }}$ order can help us to methodically sort out human organizational design by a deeper understanding of the natural science of humanity and the human science of nature; this complexity level of process learning will lead to human organizations that give meaning to mental health, economic performance and physical sanity as overall cost-reducing strategy by focusing on intrinsic models of humanistic behavior and relations. The direction of communication in management ecology will follow the interpretative, heuristic and hermeneutic method of detecting discrete environmental signals, i.e. the modern co-operation communicates with its complex outer world by an elaborated signal strategy of preception, observation and measurement. It will operate as an open learning organization as part of its greater environment, its societal framework and real economic needs. To sum it up, managerial creativity for future socio-economic co-operation does not fall from heaven; it is the fruit of clear methodical thought, hard ethical work and a liberal letting-go, based on mutual trust and true intentions for the common weal. 'In a time of drastic change it is the learner who inherits the future. The learned usually find the mselves equipped to live in a world that no longer exists.' (Eric Hoffer/1902-1983/Reflections on the Human Condition).

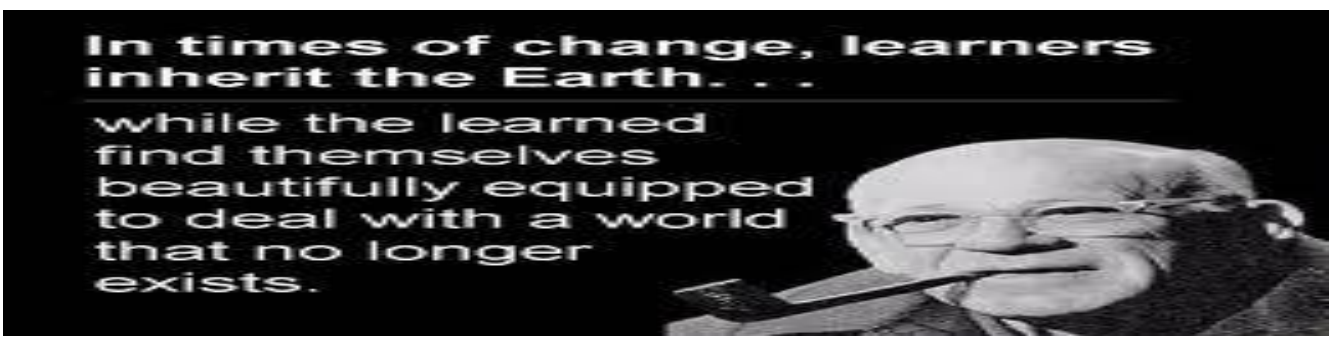

\section{References:}

Coase R.1937.The nature of the firm.Economica4: 386-405.

Foerster H.1981.Observing systems.Seaside/CA: Intersystems.

Jensen M/Meckling W.1976.The theory of the firm.JFinEcon3:305-360.

Lavoie D(ed).1991.Economics and Hermeneutics.London: Routledge.

Ternyik S.1993.Engineering Design as Learning Process.Tokyo 
Univ/presentation on Intelligent Manufacturing Systems.

Varela F.1999.Ethical Know-How.Stanford: UP.

White H.2002.Markets from networks.Princeton: UP.

www.attainable-utopias.com/tiki/CyberneticOrders 